\title{
Quantitative Review of Construction 4.0 Technology Presence in Construction Project Research
}

\author{
Pia Schönbeck *(1), Malin Löfsjögård and Anders Ansell \\ Department of Civil and Architectural Engineering, KTH Royal Institute of Technology, 10044 Stockholm, \\ Sweden; malin.lofsjogard@byv.kth.se (M.L.); anders.ansell@byv.kth.se (A.A.) \\ * Correspondence: piasch@kth.se
}

Received: 5 August 2020; Accepted: 27 September 2020; Published: 29 September 2020

\begin{abstract}
The development of technologies associated with the fourth industrial revolution is rapid. Construction 4.0 represents the architecture, engineering, construction and operations industries exploration of new technologies, equivalent to Industry 4.0 for the manufacturing industry. These concepts address multiple perspectives besides the technological, such as management and processes. The purpose of this study was to investigate to what extent research regarding construction projects addresses information and communication, automatisation or industrialisation technologies. A scoping review was the method used to perform a quantitative analysis of over two thousand journal papers published from 2015 onwards. The results show that new technologies are addressed separately, while synergy studies are uncommon. Longitudinal analyses show that there was no significant increase in journal papers concerning new technologies from 2015 to 2019. Information and communication was the search criterion with the least number of papers found. The environmental perspective of new technologies was present but the least common from 2019 to 2020. Hence, this review shows that there is an extensive research gap regarding Construction 4.0 technologies in the context of construction projects. Studies regarding synergy and environmental effects of new technologies should increase to start the progress towards a successful entry into the fourth industrial revolution.
\end{abstract}

Keywords: construction 4.0; information and communication technology; automated construction; industrial construction; project management

\section{Introduction}

The technical development towards the fourth industrial revolution will change many industries. Digitisation and automation technologies are explored within Industry 4.0 by the manufacturing industry to find beneficial effects and improve processes [1,2]. Construction 4.0 is the equivalent exploration of new technologies in the Architecture, Engineering, Construction and Operations (AECO) industry [3]. In the context of construction projects, the value of digital processes, automation and industrialised construction is still essentially unexplored [4]. Digital processes enable increased control over configurations and can transfer knowledge globally. Definition of configurations based on data from operational use can prolong building lifecycles and increase usability [5]. Automated construction methods can improve efficiency and accuracy during production [6]. In the world, the construction industry accounts for $11 \%$ of the overall emissions and $6 \%$ of the energy consumption [7]. Consumption of non-metallic minerals in the construction industry accounts for two thirds of the total resource extraction [8]. Construction 4.0 technologies have the potential to prevent unnecessary construction work and prolong lifecycles, which United Nations Environmental Programme (UNEP) identifies as essential to reduce the AECO industry environmental impact [7]. 
The concepts of Industry 4.0 and Construction 4.0 entail not only new technologies but also aspects such as organisations, management and processes [4]. There are many challenges in implementing new technologies since it will require extensive changes in business models and require new skills [9]. Initially, the application of new technologies and the transformation of procedures are resource-intensive. Therefore, potential benefits must be identified to provide an incentive for the AECO industry to apply new technology [10]. Managers of construction projects encounter technologies used in facility management, planning, design, construction and at handover. Construction projects must consequently consider synergy effects and assure minimal environmental impact in the integration of different techniques. In this study, the focus is on technologies relevant to construction projects. Three groups of Construction 4.0 technologies were analysed: information and communication, automatisation and industrialisation. The aim of this study was to investigate the presence of these techniques in research concerning construction projects. An extensive literature review was conducted to analyse more than two thousand journal papers from 2015 onwards.

\section{Background}

Construction project management starts with the analysis of large amounts of functional requirement data, which should be transferred to measurable acceptance criteria before designers' starts to develop solutions [11]. Artificial intelligence technologies that process and learn from a large amount of data can optimise the transition of functions to design solutions. This can make the development of building configurations more evidence-based and less dependent on implicit knowledge [12]. Digital processes and automated construction require the establishment of realisation methods before production starts and verification of fulfilment until delivery. Assigning feasible production methods to each design solution can reduce inefficiency and the number of changes during construction [13]. Verification of the end-product performance is mainly performed as built in construction projects [14]. However, continuous digital processing of building data from planning to handover can identify deviations and thereby prevent unnecessary rework. Digital information about the building configuration is today part of the delivery to the client. Incorrect information may have long-term implications for building performance, which affects operational use, asset and facility management [5]. Information and communication in combination with automatisation or industrialisation technologies may have synergy effects in construction projects. For example, detailed and accurate building information is a prerequisite for implementing robot techniques [15].

\subsection{Construction 4.0}

Industry 4.0 was initiated to explore how the manufacturing industry could benefit from the integration and implementation of new technologies. The concept is broad and considers many aspects of interdisciplinary technologies and collaborations, which is imperative to achieve continuous automation through different processes [4]. Integration of technologies should be considered from several perspectives, such as horizontal (network between organisations), vertical (interrelating technologies within organisations) and end-to-end (interrelating technologies through entire processes) [16]. Construction projects encounter challenges that complicate all aspects of integration. The AECO industry is fragmented and has sequential processes, which complicates horizontal and vertical integration of networks with full transparency and integration [17]. End-to-end integration is complex since diverse organisations must agree on how their different technologies can be combined [18]. The research regarding Construction 4.0 is mainly on a conceptual level and focus on new applications of existing technologies. There are few studies on realisation and the perspective of management and organisations [10].

\subsection{Information and Communication Technologies}

In construction projects, the incremental development of configurations causes inefficiency and precludes flow of information. Information and Communication Technologies (ICT) can digitally 
process large amounts of data and make it accessible throughout construction projects. In real time, the information defining the product should always be reliable and correct [19]. Studies on digital processes in the AECO industry are often associated with Building Information Modelling (BIM), but Construction 4.0 includes other digital technologies that can improve processes in construction projects. Artificial Intelligence (AI), Internet of Things (IoT), 5G and augmented reality are technologies that can be beneficial. Construction projects have issues with the insufficient definition of functional requirements [20]. Use of data from operational use can make client decisions regarding functions information based. Augmented reality provides an opportunity for stakeholders to test functionality in the design phase [21]. In addition, visualisation techniques can transfer knowledge to end-users in the handover phase [5]. Verification of the product configuration is often performed late in construction projects, which precludes proactive measures to prevent deviations [22]. Digital processes using acceptance values as conditions enables continuous monitoring and control of building performance in construction projects [23]. Knowledge transfer, decision making and efficiency can improve by using AI to analyse large amounts of data from design, construction and operational use of buildings [24]. Data from IoT sensors can contribute to an optimisation of building configurations and proactive activities in operational use [4]. The implementation of 5G networks offers fast and reliable connections, enabling the use of digital technology in remote construction sites [25].

\subsection{Automated and Industrial Techniques}

The production methods are determined gradually and success is often dependent on implicit knowledge of individuals in construction projects [26]. This work process will be obsolete with automated construction since predefined products and customised production methods are required [27]. Automated construction includes different techniques, such as prefabrication of building parts, ready-made modules and robot techniques. Processes associated with these technologies are similar to those of the manufacturing industry; the products should be developed, defined and associated with realisation technologies before production starts [28]. The construction industry is already using prefabricated building parts and modules, which enable development and testing before realisation. Efficiency during construction can potentially increase with prefabricated parts or modules produced off site [6]. Production of building parts on or off site with 3D printing of different materials (i.e., additive manufacturing) can adapt and optimise constructions for specific purposes [3]. Development of robot technologies that can operate in unstructured environments facilitates use on construction sites. Moreover, the use of $5 \mathrm{G}$ networks allows for connections between different robot systems to form a production chain [15]. Repetitive construction procedures, such as building masonry walls, can be performed with robots instead of manual labour [29]. Combining different automated production methods can customise the realisation of a building and thereby reduce the risk for product deviation.

\subsection{Environmental Perspective of New Technologies}

Design solutions that are not connected to measurable functions [11] or feasible production methods [14] increase unnecessary construction work and the environmental impact. The use of digital processes combined with reverse engineering reduces rework in renovation projects [30]. Use of AI techniques enables analyses of data to make reliable calculations of construction material consumption [31]. This knowledge provides an opportunity for proactive measures to reduce environmental impact. Automated construction requires the establishment of realisation methods before production starts. Assigning feasible production methods to each design solution can reduce unnecessary construction work due to deviations from the intended end-product [13]. The use of digital processes in combination with automated construction can identify any deviations and improve control over building configurations [32]. During production, digital processes and automated technologies can improve efficiency and reduce rework. Reduction of unnecessary construction work is an essential factor for the AECO industry to fulfil societal requirements on environmental sustainability [7]. The potential 
effects of information and communication, automatisation and industrialisation technologies are diverse. To summaries this section, Figure 1 shows how the construction 4.0 technologies addressed in this study may affect project management and environmental impact.

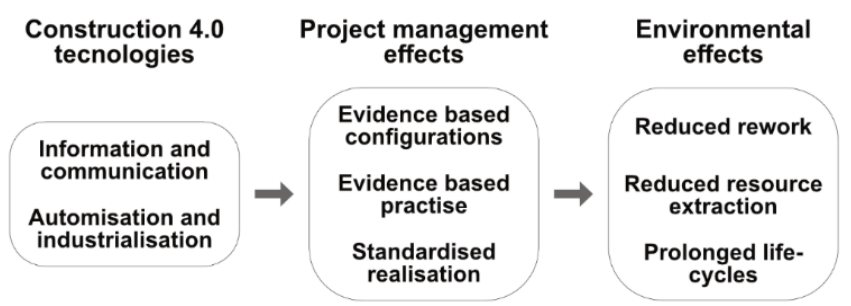

Figure 1. The potential effects of new technologies on project management and the environment.

\section{Objectives}

The AECO industry is at the beginning of exploring how technologies of the fourth industrial revolution can be used to optimise different aspects, such as the management of construction projects. This study explores the presence of information and communication, automatisation or industrialisation technologies related to project management and environmental impact. The aim was to conduct a quantitative literature review to answer the following research questions (RQ):

RQ1. To what extent do construction project studies address subjects associated with information and communication, automatisation or industrialisation technologies?

RQ2. To what extent are environmental phrases present in studies concerning information and communication, automatisation or industrialisation technologies and construction projects?

\section{Materials and Methods}

The method used was a scoping review using quantitative analysis of papers to establish numbers and presence of phrases. Scoping reviews is suitable for overviews of key concepts and research gaps of emerging areas [33]. Therefore, this method was chosen to examine the topic of information and communication, automatisation or industrialisation technologies in construction projects. The concept of Construction 4.0 covers many perspectives. However, this study limited the scope to the technologies applicable in the management of construction projects; information and communication, automatisation and industrialisation. Table 1 shows the search criteria used in the databases of Scopus (Elsevier) and Web of Science (Clarivate Analytics) to identify relevant literature.

Table 1. The criteria with keywords used to search for journal papers in selected databases.

\begin{tabular}{ccc}
\hline Criteria & Words & \\
\hline $\mathrm{C} 1$ & Construction & AND \\
& Project & AND \\
& Information & AND \\
& Communication & \\
\hline $\mathrm{C} 2$ & Construction & AND \\
& Project & AND \\
& Automation & OR \\
& Industrial & \\
\hline $\mathrm{C} 3$ & Construction & AND \\
& Project & AND \\
& Management & \\
\hline
\end{tabular}

The aim was to investigate how many research papers concerning construction projects that address information and communication, automatisation or industrialisation technologies from 2015 to 2020 
using the criteria $\mathrm{C} 1$ and $\mathrm{C} 2$. In addition, the $\mathrm{C} 3$ search criterion was used to examine if research about construction project management addresses these technologies. Figure 2 shows the overall design of the literature review. Separate analyses for each search group were conducted in the text analysis.

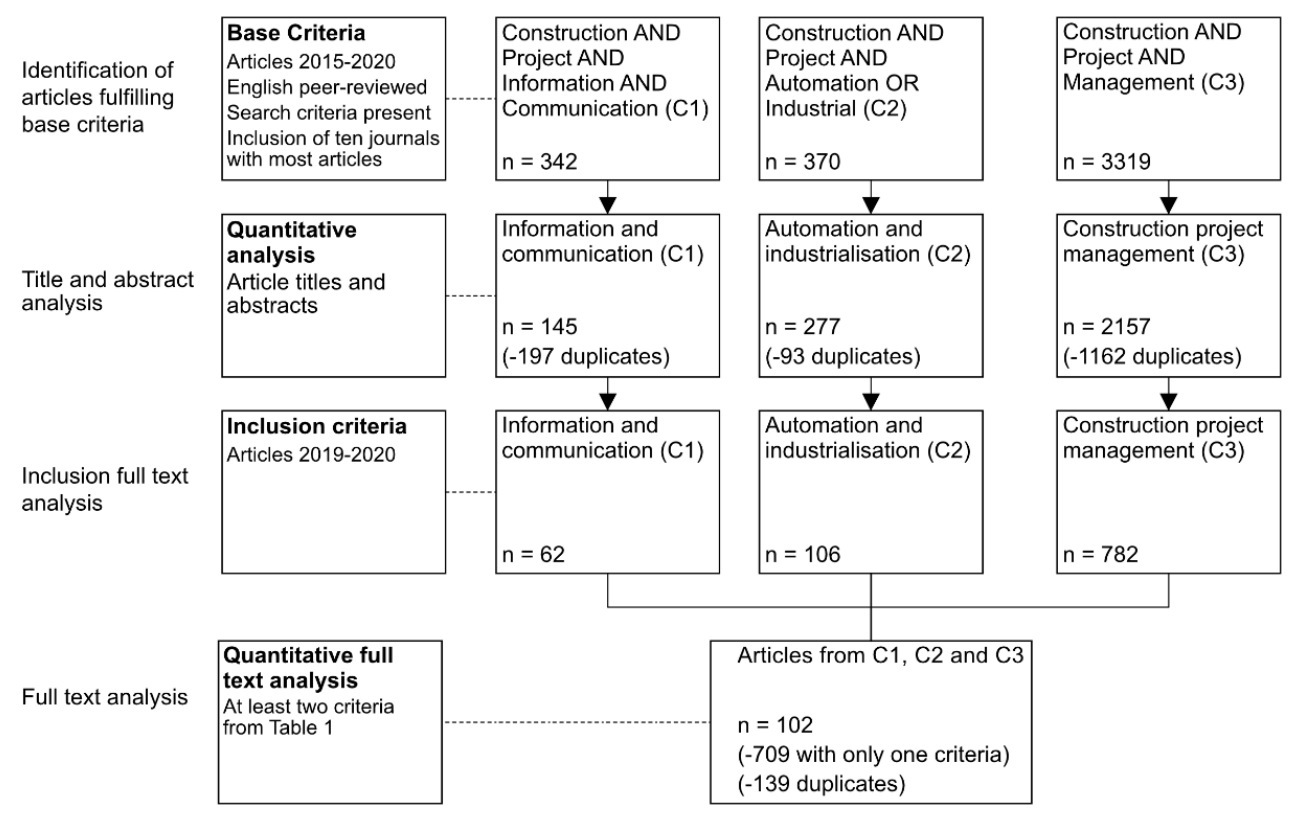

Figure 2. Flow diagram of the implementation of the literature review.

The following base criteria for the search was chosen to ensure a common level of quality for included papers:

- Journal papers published from 2015 and onwards

- Peer-reviewed journal papers written in English

- Search criteria present (see Table 1)

- Papers published in the ten Scopus indexed journals with most search findings

Analysis of 2342 unique journal papers was conducted, some of which belonged to more than one search group (i.e., C1, C2 and C3) [34] (Supplementary Materials). The abstracts of all included papers were analysed to find key phrases. In scoping reviews, the purpose is to explore the presence of a specific topic without assessing the quality of the included papers [33].

However, two quality parameters were used in this study as base criteria for the journals, peer-review and Scopus index. All Scopus indexed journals are quality assured once a year regarding six quality parameters; self-citation rate, total citation rate, CiteScore, number of articles, full-text and abstract extraction on Scopus.com. Moreover, there are continuous scans for outlier journals and the research community can report concerns about publishers or journals [35]. Table 2 presents the journals containing the included papers.

Papers published in 2019 or 2020 that fulfilled two search criteria from Table $1(n=102)$ were included in the full text analysis. Use of standardised protocols in MATLAB Text Analytics Toolbox [36] improved reliability by ensuring repeatability and reduced observer bias. The following text was preprocessed before analysing the papers to increase reliability:

- Punctuation removed

- Conversion of all text to lowercase

- Textual sequences were broken down into tokens

- Dates, symbols, single letters, names

- Non relevant words were excluded 
Table 2. The journals of the included papers.

\begin{tabular}{cccc}
\hline Journal & Publisher & ISSN & eISSN \\
\hline Automation in Construction & Elsevier & $0926-5805$ & $1872-7891$ \\
Buildings & MDPI & & $2075-5309$ \\
Construction Innovation & Emerald & $2044-124 X$ & $2044-1258$ \\
Built Environment Project and Asset Management & Emerald & $1471-4175$ & $1477-0857$ \\
Construction Management and Economics & Taylor \& Francis & $0144-6193$ & $1466-433 X$ \\
Engineering Construction and Architectural Management & Emerald & $0969-9988$ & $1365-232 X$ \\
International Journal of Construction Education and Research & Taylor \& Francis & $1557-8771$ & $1550-3984$ \\
International Journal of Construction Management & Taylor \& Francis & $1562-3599$ & \\
International Journal of Project Management & Elsevier & $0263-7863$ & \\
Journal of Civil Engineering and Management & Taylor \& Francis & $1392-3730$ & $1822-3605$ \\
Journal of Cleaner Production & Elsevier & $0959-6526$ & $1879-1786$ \\
Journal of Computing in Civil Engineering & ASCE & $0887-3801$ & \\
Journal of Construction Engineering and Management & ASCE & $0733-9364$ & $1943-7862$ \\
Journal of Engineering Design and Technology & Emerald & $1726-0531$ \\
Journal of Intelligent and Robotic Systems & Springer Nature & $0921-0296$ & $1573-0409$ \\
Journal of Management in Engineering & ASCE & $0742-597 X$ & $1943-5479$ \\
KSCE Journal of Civil Engineering & Springer Nature & $1226-7988$ & $1976-3808$ \\
Resources, Conservation and Recycling & Elsevier & $0921-3449$ & $1879-0658$ \\
Sustainability & MDPI & $2071-1050$ & \\
\hline
\end{tabular}

The validity of a scoping review is dependent on the choice of search criteria and key phrases. The developed standardised method can ensure accuracy in different contexts since exchange of phrases is possible. Figure 3 shows the MATLAB protocol used for the word count of the texts.

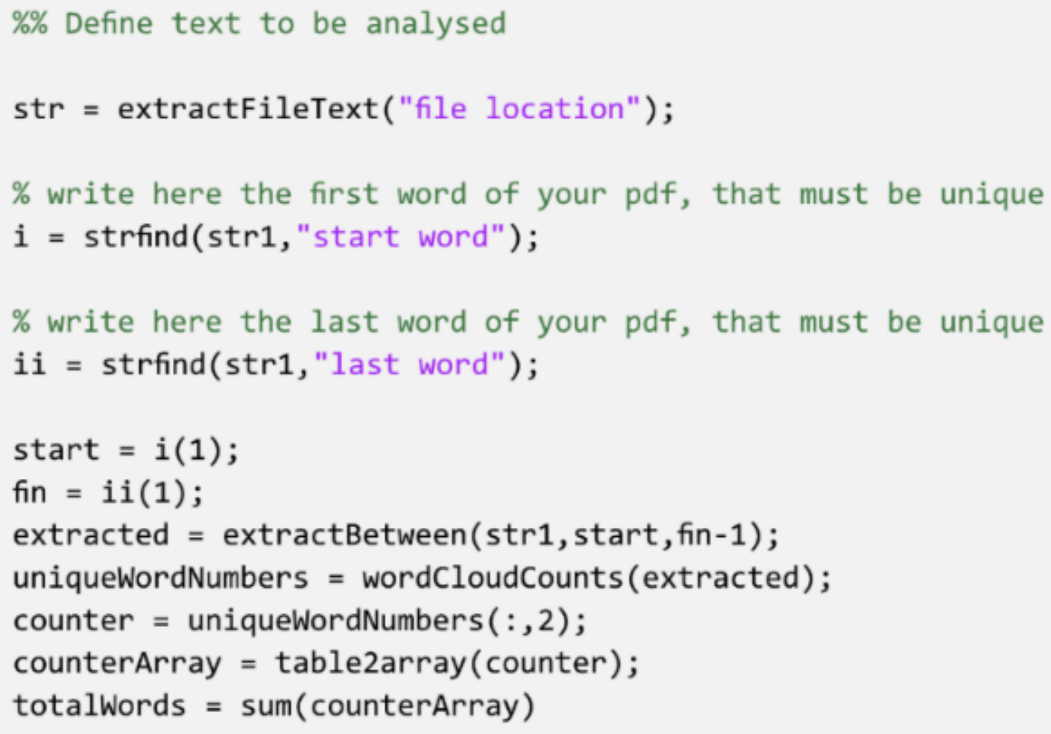

Figure 3. The protocol used for the overall word count of the texts.

Figure 4 shows the protocol used in MATLAB to find most common single and two word combinations in titles, abstracts or full text. To find all occurrences in the specific search for Construction 4.0 technology and environmental terms, the stem word with an asterisk $\left(^{*}\right)$ at the end was used when applicable to include all endings. 


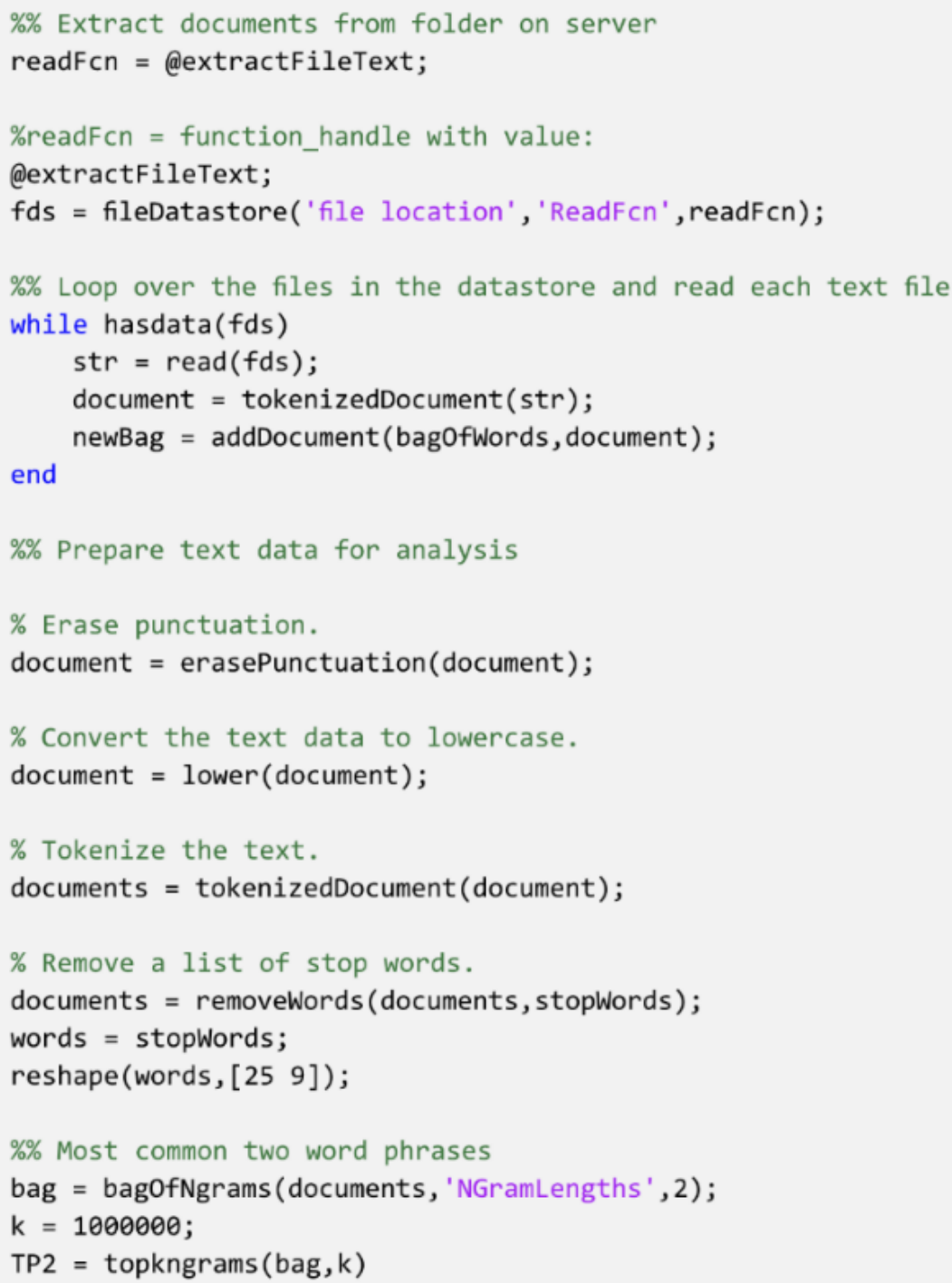

Figure 4. The protocol used for text analysis of words and phrases.

\section{Results}

The result of this quantitative review shows that studies regarding Construction 4.0 technologies are not frequently in construction project research. In addition, there has been no significant increase from 2015 onwards of research regarding the rapidly developing technologies associated with the fourth industrial revolution. Papers addressing information and communication (C1) or automation and industrialisation (C2) in the context of construction projects were few compared to those concerning management (C3). Studies considering two or three of the search criteria were uncommon, with C2 and $\mathrm{C} 3$ being the most frequent combination, as Figure 5 shows. 


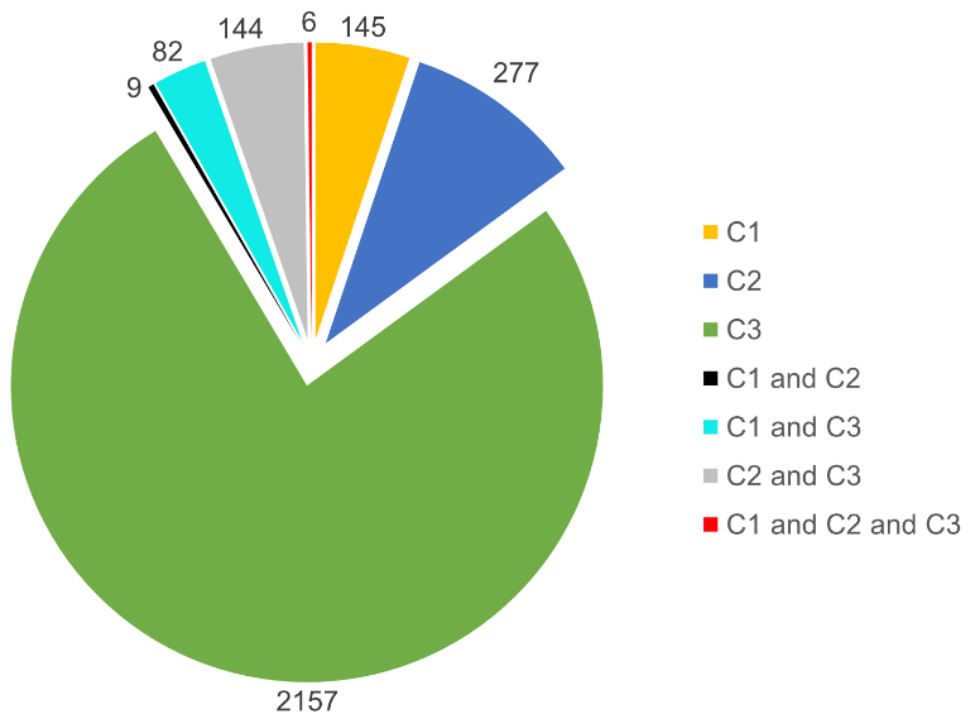

Figure 5. The number of papers per search criteria and combinations of them.

Figure 6 presents the nineteen journals that published the included papers. Of them, seven of those contained all search criteria, while eight contained only one.

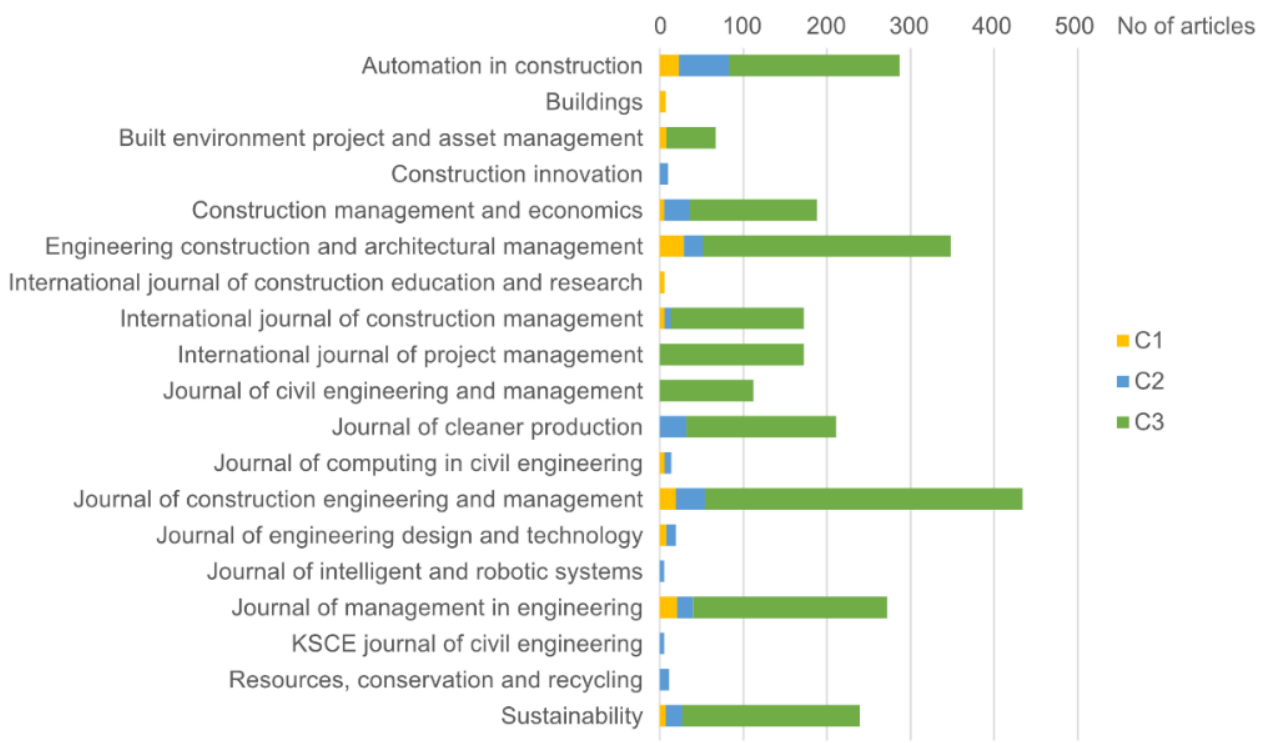

Figure 6. The journals where the included papers were published, presented per search criteria.

In general, few journals contained papers from the $\mathrm{C} 1$ and $\mathrm{C} 2$ group. The findings presented in Figures 5 and 6 both indicate that techniques associated with Construction 4.0 are mainly studied separately. The potential synergy effects of technologies within information and communication, automatisation or industrialisation are therefore rarely considered.

The number of papers per criteria and publishing year is shown in Figure 7; note that papers from 2020 are excluded since the whole year cannot be reported. Papers concerning construction project management have increased from the start of 2015 to the end of 2019. The most infrequent papers were those containing both $\mathrm{C} 1$ and $\mathrm{C} 2$ or all search criteria. The relative increase of papers from 2015 to 2019 was greatest for papers regarding automation or industrialisation in combination with project management, increasing from 12 to 38 studies. Only 140 of the 1737 studies concerning construction project management fulfilled another search criterion. 


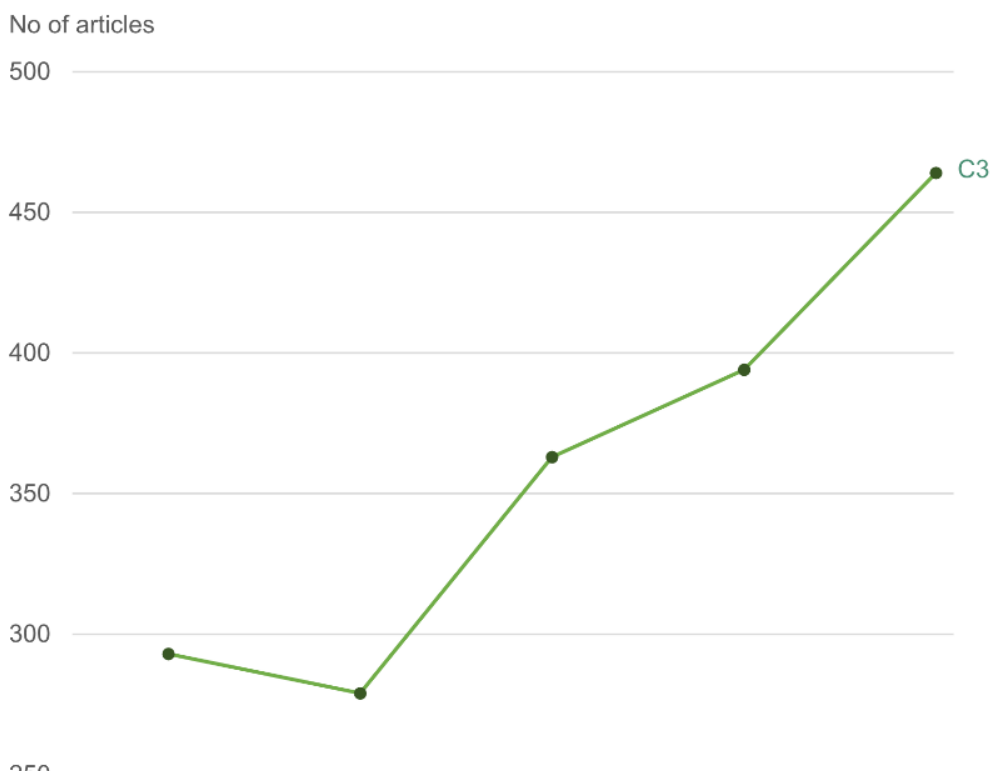

250

200

150

100

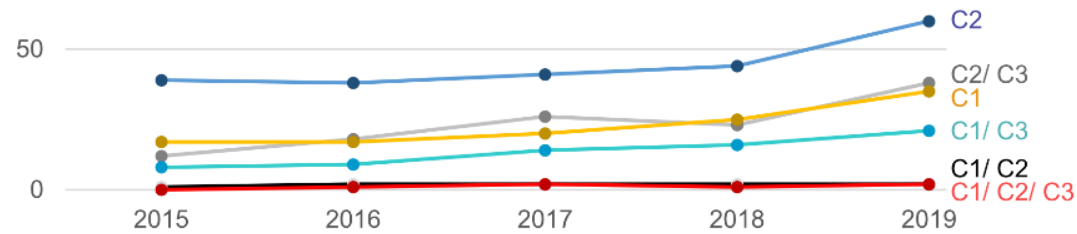

Figure 7. The number of papers per search area and year.

The results presented in Figure 8 show the ten most common two word phrases in the titles, abstracts or full texts. All search areas contained the following phrases; "building information", "construction management", "project management", "project delivery" and "supply chain". Criterion C1 papers were the only ones containing "information" in combination with "communication". Papers fulfilling criterion C2 contained the phrase "industrial construction", while the combination of "automation construction" only was found in the full text analysis from 2019-2020. The phrases "building information" and "information modeling" was amongst the ten most common phrase in papers fulfilling the $\mathrm{C} 3$ criterion. Indicating that research regarding construction project management considers building information, but few of the other studied technologies. The results of the full text analysis show that "management" and "automation" were among the most common in the phrases. 


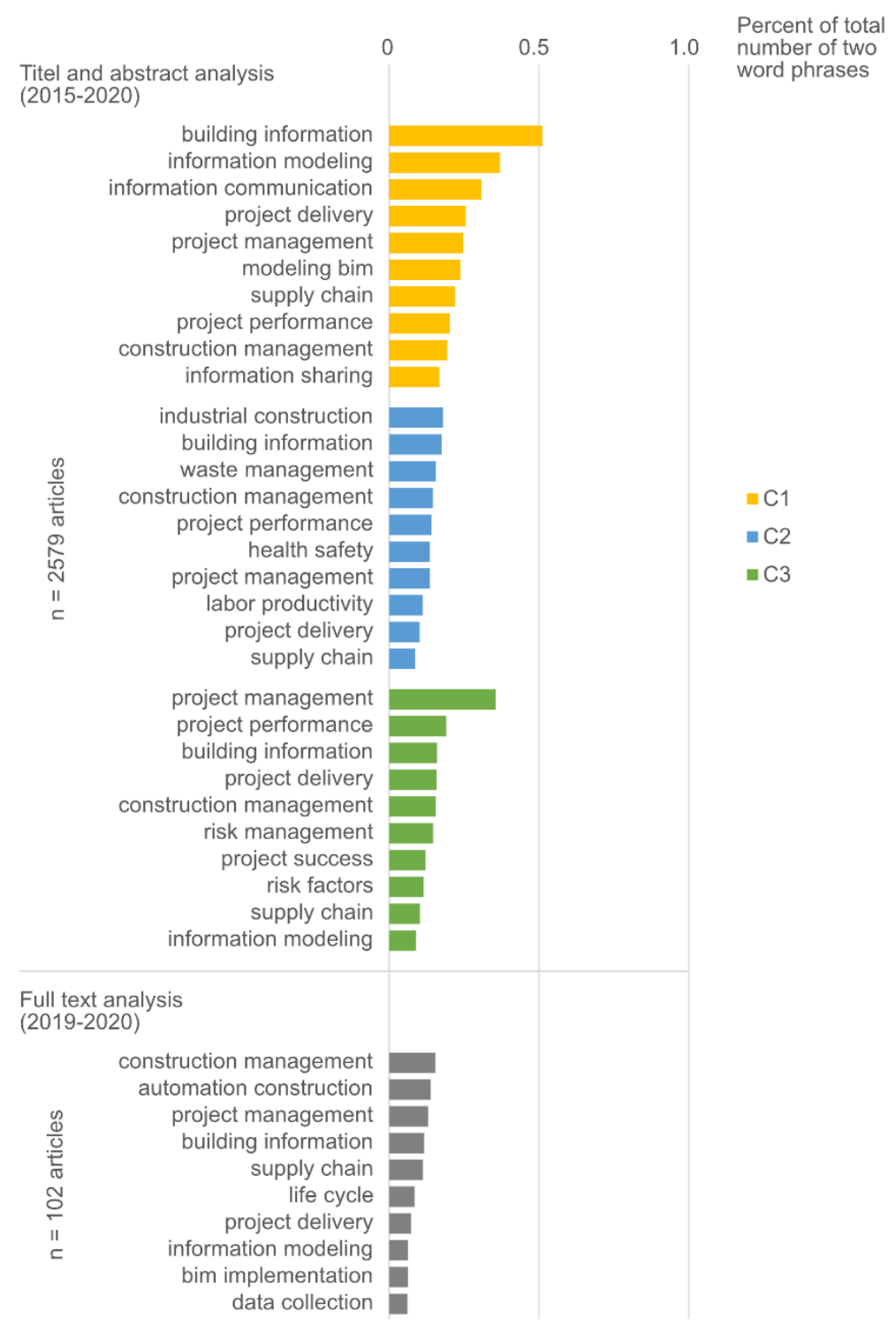

Figure 8. Most common two word phrases in the included papers.

Figure 9 shows the results from the search for specific two word phrases associated with Construction 4.0 techniques. The most frequent was "building information" OR "bim", which is consistent with the results in Figure 8 showing that "building information" was among the ten most common two word phrases of all search criteria. Generally, techniques associated with automation or industrialisation were more common than those of information and communication. Prefabrication requires information technologies to define and develop configurations, which is consistent with the finding that this phrase was most common in $\mathrm{C} 1$ papers. The full text analysis shows that there has been no significant increase in research regarding any of the studied techniques during 2019-2020. 


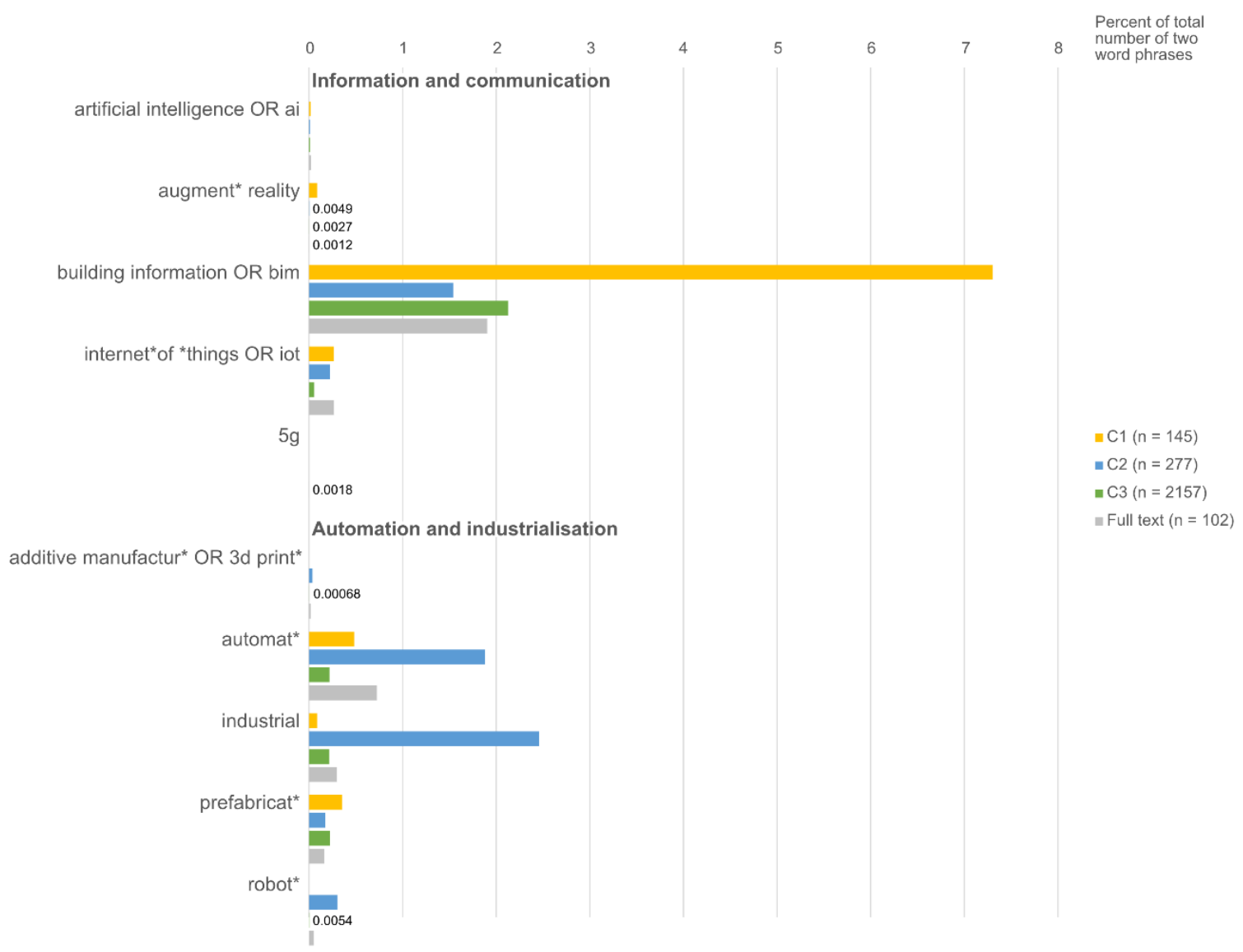

Figure 9. Presence of technologies associated with construction 4.0 in the included papers.

The availability of phrases containing sustainability and environmental terms were studied in papers of each search criterion. All two word phrases with "environment", "life*cycle", "resource*" or "sustainab" was identified. The environmental perspective is present in all of the search groups and the full text analysis, as shown in Figure 10. Phrases containing environment and sustainability were most common in C2 and C3 papers, while lifecycle was most frequent in C1 papers. The environmental terms were among the least common in the 2019-2020 full text analysis, which indicates that studies with this perspective are not increasing.

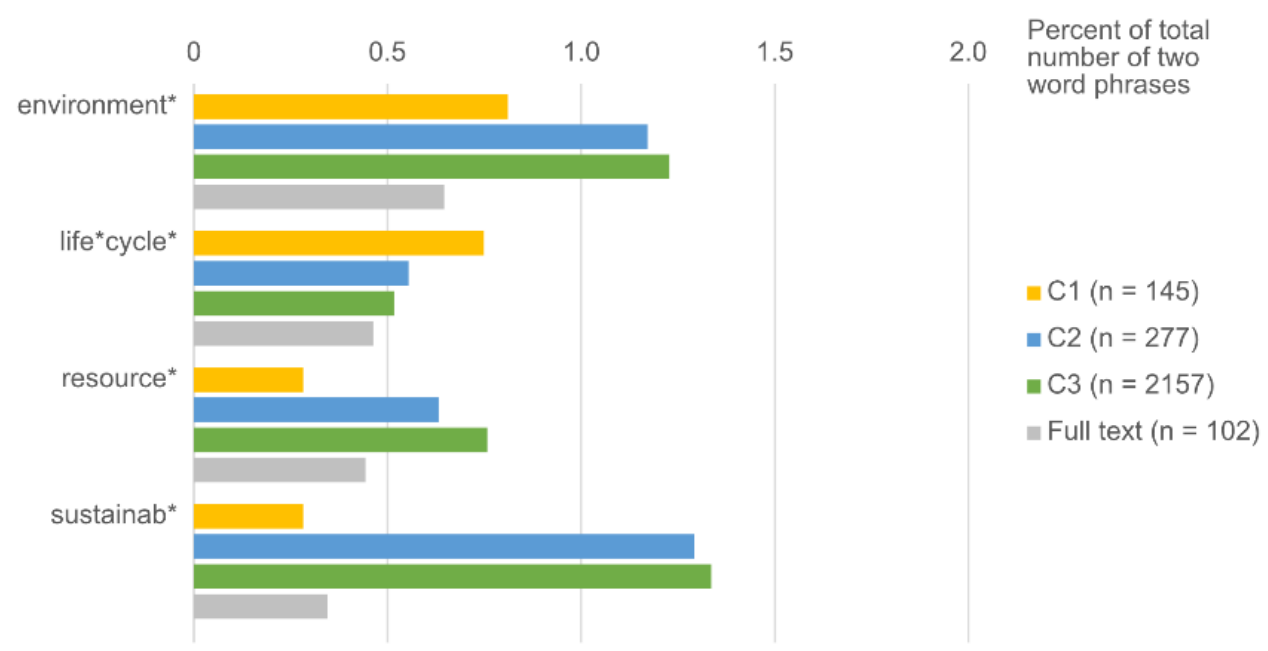

Figure 10. The occurrence of terms associated with the environment and sustainability for each search criterion. 


\section{Discussion}

The development of technologies associated with the fourth industrial revolution will change the AECO industry. Digital processes can facilitate the development of standardised products based on evidence from large amounts of data, which can optimise quality and functionality [24]. Automated construction can streamline realisation and prevent product deviation [6]. However, this review shows that studies concerning Construction 4.0 technologies are uncommon in the context of construction projects. Digital analyses of data from construction projects provide information that may optimise the use of automation and industrialisation techniques [6], but the combination of criteria $\mathrm{C} 1$ and C2 were among the least common. It is essential to explore the synergy effects of Construction 4.0 techniques in construction projects to optimise benefits and meet future environmental challenges. Scoping reviews have limitations since the purpose is to get an overview without more detailed quality assessments of the included studies. The strengths of scoping reviews are that the method is systematic and repeatable [37]. In this study, the standardised text analysis enables repeated measurements in future studies. The base parameters for including papers ensured a common quality level but resulted in the exclusion of some studies that fulfilled the search criteria. There may be papers with other search criteria than the chosen in this study that addresses new technologies. However, the assessment was that the analyses of the great number of papers provide a reliable overview of existing research gaps.

\subsection{Information and Communication Technologies}

A large part of construction project research focuses on the implementation of building information modelling. In the longitudinal analyses, the findings show that information and communication technologies in combination with project management were among the least common, with a maximum of 21 papers in 2019. Information and communication technologies can facilitate the automation of manual processes and improve the reliability of building information. For example, AI can automate the processing of building information to support project management [31]. In the investigated papers, artificial intelligence was among the least mentioned technologies. Construction sites can have remote locations and 5G technology is a prerequisite to use ICT on site [25]. However, 5G was only present in six papers of the over two thousand papers analysed. Internet of things is a technique that has been under development for more than a decade and is currently under implementation, which can improve the management and sustainability during a building lifecycle [3]. This technique was least mentioned in project management papers despite the potential beneficial effect. Augmented reality enables testing of functions during the design phase and visualising the decided configuration during production, which is essential for delivering buildings with intended functionality [38]. In the text analysis, augmented reality was present in 20 papers.

\subsection{Automated and Industrial Techniques}

Automation and industrialisation are interconnected with ICT and project management, but combinations of these search criteria were only present in 9 and 144 papers, respectively. Additive manufacturing makes building designs flexible regarding configuration and materials [3], which can reduce material consumption [31]. Among the automation and industrialisation techniques, additive manufacturing was most common in the full text analysis from 2019 to 2020 . Use of robots enables automation and several interconnected contributes to more industrialised construction operations [15]. Robotics is dependent on ICT techniques, such as 5G, for communications between different systems and to access building information. There were no occurrences of robots in the ICT papers of this review. Standardised realisation methods customised for specific configurations increases efficiency and prevents end-product deviations [6]. Prefabrication of building parts and modules are already a reality in construction and papers from all search groups contained this technique, but was mostly mentioned in $\mathrm{C} 1$ papers indicating a close relation to ICT [39]. 


\subsection{Environmental Perspective of New Technologies}

Regarding the environmental perspective of Construction 4.0 technologies, it was present in papers of all search criteria. Use of AI technologies to analyse and interpret large amounts of data can provide clear definitions of building configurations [5]. Thus, unnecessary construction work due to ambiguities can be reduced [14]. Prefabrication and additive manufacturing enable the use of new materials and control over resource extraction [31]. The full text analysis of papers from 2019-2020 showed no increase regarding the environmental perspective. In fact, the environmental phrases in those studies were among the least frequent. Most common were the environmental phrases in studies of project management and automatisation or industrialisation. The resource perspective was least considered in ICT studies, even though digital analyses and AI applications have the potential to optimise and decrease material consumption. At present, the environmental impact of the AECO industry is significant and any measures that reduce it are important to increase sustainability [7].

\section{Conclusions}

The purpose of this study was to explore to which extent information and communication, automation or industrialisation technologies were present in studies of construction projects. In addition, the presence of environmental phrases was studied. Findings from this review clearly show that there are extensive research gaps regarding studies exploring new technologies in the context of construction projects. Eight percent of the papers addressing construction project management from 2015 to 2019 also considered information and communication, automation or industrialisation techniques. Studies that contained more than one search criterion from 2015 to 2020 were found in nine percent of the papers. These findings indicate that the synergy perspective is underexplored. Environmental phrases were most uncommon in papers from 2019 to 2020, which implies that this perspective of new technologies is not increasingly studied. Implementation of new technologies will change the management of construction projects with increased automation of operations. The value of this study is the identification of research gaps regarding new technologies in the context of construction projects. Studies that investigate the synergy effects of combining technologies should increase. For example, reliable real time digital twins of buildings require exploration of what technologies that require integration. At construction sites, this may include digital analysis, 5G for accessibility and robots that continuously scan the building during production. Furthermore, studies of how new technologies may be used to define and maintain intended configurations can contribute to reducing unnecessary construction work and material consumption. Hence, reduce environmental impact and increase sustainability of construction projects.

Supplementary Materials: The references for the papers investigated in text analysis are available online at http://www.mdpi.com/2075-5309/10/10/173/s1.

Funding: Region Stockholm funded this research (grant number LDR6262). KTH Royal Institute of Technology funded the APC.

Acknowledgments: A grant from Region Stockholm (previous Stockholm county council) enabled this research, for which the authors are most grateful.

Conflicts of Interest: The authors declare no conflict of interest.

\section{References}

1. Lasi, H.; Fettke, P.; Kemper, H.-G.; Feld, T.; Hoffmann, M. Industry 4.0. Bus. Inf. Syst. Eng. 2014, 6, $239-242$. [CrossRef]

2. Ali, U.; Kidd, C. Configuration Management Process Capabilities. In Proceedings of the 2nd International Through-life Engineering Services Conference, Cranfield, UK, 5-6 November 2013; Elsevier: Amsterdam, The Netherlands, 2013; pp. 169-172.

3. Craveiro, F.; Duarte, J.P.; Bartolo, P.; Bartolo, P. Additive manufacturing as an enabling technology for digital construction: A perspective on Construction 4.0. Autom. Constr. 2019, 103, 251-267. [CrossRef] 
4. Oesterreich, T.D.; Teuteberg, F. Understanding the implications of digitisation and automation in the context of Industry 4.0: A triangulation approach and elements of a research agenda for the construction industry. Comput. Ind. 2016, 83, 121-139. [CrossRef]

5. Pärn, E.A.; Edwards, D.J.; Sing, M. The building information modelling trajectory in facilities management: A review. Autom. Constr. 2017, 75, 45-55. [CrossRef]

6. Viana, D.D.; Tommelein, I.D.; Formoso, C.T. Using Modularity to Reduce Complexity of Industrialized Building Systems for Mass Customization. Energies 2017, 10, 1622. [CrossRef]

7. IEA; UNEP. Global Status Report, Towards a Zero-Emission, Efficient and Resilient Buildings and Construction Sector. In Proceedings of the 2018 United Nations Climate Change Conference, Katowice, Poland, 2-15 December 2018.

8. Oberle, B.; Bringezu, S.; Hatfield-Dodds, S.; Hellweg, S.; Schandl, H.; Clement, J. Global Resources Outlook: 2019; International Resource Panel, United Nations Envio: Paris, France, 2019.

9. Schneider, P. Managerial challenges of Industry 4.0: An empirically backed research agenda for a nascent field. Rev. Manag. Sci. 2018, 12, 803-848. [CrossRef]

10. Maskuriy, R.; Selamat, A.; Ali, K.N.; Maresova, P.; Krejcar, O. Industry 4.0 for the Construction Industry-How Ready Is the Industry? Appl. Sci. 2019, 9, 2819. [CrossRef]

11. Toor, S.-U.-R.; Ogunlana, S.O. Beyond the 'iron triangle': Stakeholder perception of key performance indicators (KPIs) for large-scale public sector development projects. Int. J. Proj. Manag. 2010, 28, 228-236. [CrossRef]

12. Hamledari, H.; Azar, E.R.; McCabe, B. IFC-Based Development of As-Built and As-Is BIMs Using Construction and Facility Inspection Data: Site-to-BIM Data Transfer Automation. J. Comput. Civ. Eng. 2018, 32, 04017075. [CrossRef]

13. Eleftheriadis, S.; Duffour, P.; Mumovic, D. Participatory decision-support model in the context of building structural design embedding BIM with QFD. Adv. Eng. Inform. 2018, 38, 695-711. [CrossRef]

14. Parvan, K.; Rahmandad, H.; Haghani, A. Inter-phase feedbacks in construction projects. J. Oper. Manag. 2015, 39-40, 48-62. [CrossRef]

15. Bock, T. The future of construction automation: Technological disruption and the upcoming ubiquity of robotics. Autom. Constr. 2015, 59, 113-121. [CrossRef]

16. Liao, Y.X.; Deschamps, F.; Loures, E.D.F.R.; Ramos, L.F.P. Past, present and future of Industry 4.0-A systematic literature review and research agenda proposal. Int. J. Prod. Res. 2017, 55, 3609-3629. [CrossRef]

17. Liu, Y.; Van Nederveen, S.; Hertogh, M. Understanding effects of BIM on collaborative design and construction: An empirical study in China. Int. J. Proj. Manag. 2017, 35, 686-698. [CrossRef]

18. Rivera, F.M.-L.; Mora-Serrano, J.; Valero, I.; Oñate, E. Methodological-Technological Framework for Construction 4.0. Arch. Comput. Methods Eng. 2020, 1-23. [CrossRef]

19. Monticolo, D.; Badin, J.; Gomes, S.; Bonjour, E.; Chamoret, D. A meta-model for knowledge configuration management to support collaborative engineering. Comput. Ind. 2015, 66, 11-20. [CrossRef]

20. Kim, T.W.; Cha, S.H.; Kim, Y. A framework for evaluating user involvement methods in architectural, engineering, and construction projects. Arch. Sci. Rev. 2016, 59, 136-147. [CrossRef]

21. Santos, R.; Costa, A.A.; Grilo, A. Bibliometric analysis and review of Building Information Modelling literature published between 2005 and 2015. Autom. Constr. 2017, 80, 118-136. [CrossRef]

22. Kiviniemi, A. Requirements management interface to building product models. In Department of Civil and Environmental Engineering; Stanford University: Stanford, CA, USA, 2005.

23. Ding, L.; Li, K.; Zhou, Y.; Love, P.E. An IFC-inspection process model for infrastructure projects: Enabling real-time quality monitoring and control. Autom. Constr. 2017, 84, 96-110. [CrossRef]

24. Mohammadpour, A.; Karan, E.; Asadi, S. Artificial Intelligence Techniques to Support Design and Construction. In Proceedings of the 36th International Symposium on Automation and Robotics in Construction (ISARC), Banff, AB, Canada, 21-24 May 2019; pp. 1282-1289.

25. Reja, V.K.; Varghese, K. Impact of 5G Technology on IoT Applications in Construction Project Management. In Proceedings of the 36th International Symposium on Automation and Robotics in Construction (ISARC), Banff, AB, Canada, 21-24 May 2019; pp. 209-217.

26. Sun, M.; Fleming, A.; Senaratne, S.; Motawa, I.; Yeoh, M.L. A change management toolkit for construction projects. Arch. Eng. Des. Manag. 2006, 2, 261-271. [CrossRef] 
27. Asún, R.A.; Rdz-Navarro, K.; Alvarado, J.M. Developing Multidimensional Likert Scales Using Item Factor Analysis: The Case of Four-point Items. Soc. Methods Res. 2016, 45, 109-133. [CrossRef]

28. Lessing, J.; Stehn, L.; Ekholm, A. Industrialised house-building-Development and conceptual orientation of the field. Constr. Innov. 2015, 15, 378-399. [CrossRef]

29. Bruckmann, T.; Mattern, H.; Spenglerc, A.; Reichert, C.; Malkwitz, A.; König, M. Automated construction of masonry buildings using cable-driven parallel robots. In Proceedings of the 33rd International Symposium on Automation and Robotics in Construction (ISARC), Auburn, AL, USA, 18-21 July 2016; pp. 1-8.

30. Ding, Z.; Liu, S.; Liao, L.; Zhang, L. A digital construction framework integrating building information modeling and reverse engineering technologies for renovation projects. Autom. Constr. 2019, 102, 45-58. [CrossRef]

31. De Soto, B.G.; Adey, B.T. Preliminary Resource-based Estimates Combining Artificial Intelligence Approaches and Traditional Techniques. In Proceedings of the Creative Construction Conference (CCC), Budapest, Hungary, 25-28 June 2016; pp. 261-268.

32. Whyte, J.; Stasis, A.; Lindkvist, C. Managing change in the delivery of complex projects: Configuration management, asset information and 'big data'. Int. J. Proj. Manag. 2016, 34, 339-351. [CrossRef]

33. Tricco, A.C.; Lillie, E.; Zarin, W.; O’Brien, K.K.; Colquhoun, H.L.; Kastner, M.; Levac, D.E.; Ng, C.; Sharpe, J.P.; Wilson, K.; et al. A scoping review on the conduct and reporting of scoping reviews. BMC Med. Res. Methodol. 2016, 16, 15. [CrossRef]

34. Schönbeck, P.; Löfsjögård, M.; Ansell, A. References for Articles Included in Text Analysis. 2020. Available online: https://doi.org/10.5281/zenodo.3973049 (accessed on 5 August 2020).

35. Elsevier. Content Policy and Selection. 2020. Available online: https://www.elsevier.com/solutions/scopus/ how-scopus-works/content/content-policy-and-selection (accessed on 17 June 2020).

36. MathWorks. Text Analytics Toolbox ${ }^{\mathrm{TM}}$ Examples. 2020. Available online: https://se.mathworks.com/products/ text-analytics.html (accessed on 2 July 2020).

37. Grant, M.J.; Booth, A. A typology of reviews: An analysis of 14 review types and associated methodologies. Health Inf. Libr. J. 2009, 26, 91-108. [CrossRef]

38. Li, X.; Wu, W.; Shen, Q.; Wang, X.; Teng, Y. Mapping the knowledge domains of Building Information Modeling (BIM): A bibliometric approach. Autom. Constr. 2017, 84, 195-206. [CrossRef]

39. Chen, F.; Power, N.; Collins, J.J. A Stakeholder Contribution Pattern in Requirements Decision-Making: An Empirical Study in Enterprise Development. In Proceedings of the 24th IEEE International Requirements Engineering Conference Workshops (REW), Beijing, China, 12-16 September 2016; pp. 289-295. 